\title{
AVALIAÇÃO DA TOXICIDADE DE EXTRATOS DE CEPAS DE CIANOBACTÉRIAS COM DIFERENTES ORGANISMOS-TESTE
}

\section{Aline Domingues Batista \\ Lais Yuko Suzuki Emília Kiyomi Kuroda}

RESUMO: O aumento da concentração de nutrientes nos ecossistemas aquáticos principalmente com nitrogênio e fósforo, pode ocasionar a eutrofização dos corpos de água. Certas condições climáticas podem conduzir à quebra do equilíbrio biológico do meio aquático e favorecer o aparecimento de florações ou "blooms" de cianobactérias, com alterações substanciais na qualidade da água ou efluente. $O$ tipo mais comum de intoxicação envolvendo cianobactérias está associado às hepatotoxinas, com destaque às microcistinas - MCs. Os bioensaios foram introduzidos na Resolução ํo. 357/05 do Conselho Nacional do Meio Ambiente - CONAMA estabelecendo que o efluente não deverá causar ou possuir potencial para causar efeitos tóxicos aos organismos aquáticos no corpo receptor e que os critérios de toxicidade devem se basear em resultados de ensaios de ecotoxicidade padronizados utilizando organismos aquáticos. O objetivo desse trabalho foi avaliar a toxicidade de extratos de três cepas de cianobactérias / Microcystis, uma não tóxica M. sp. NPDC, e duas cepas comprovadamente toxigênicas, M sp. TAC95 e M sp. NPLJ4, com diferentes organismos-teste: Artemia salina, Daphnia magna, Ceriodaphnia dubia e Pseudokirchneriella subcapitata. Os valores obtidos de CL50, CE50 e Cl50 indicaram que para os organismos utilizados a ordem crescente de toxicidade correspondente aos extratos das cepas foi NPDC, NPLJ4 e TAC95. Os valores de Fator de Toxicidade - FT obtidos mostraram que todos os extratos das cepas de cianobactérias / Microcystis apresentaram elevada toxicidade. Pelos valores apresentados, pode-se observar que para todos os organismos-teste os extratos das cepas apresentaram valores de FT bem superiores ao limite estabelecido (FT:8). 
Palavras-chave: cianobactérias, microcistinas, ensaios de ecotoxicidade.

\section{INTRODUÇÃO}

A eutrofização dos corpos de água, decorrente do aumento de concentração de nutrientes, pode ocorrer de forma natural (processo lento, porém contínuo) ou artificial (decorrente de atividades antrópicas). Sob certas condições de temperatura, incidência de luz e velocidade de ventos, essa condição pode conduzir à quebra do equilíbrio biológico do meio aquático e favorecer o aparecimento de florações ou "blooms" de determinadas espécies fitoplanctônicas, com alterações substanciais na qualidade da água incluindo: redução do oxigênio dissolvido, perda das qualidades cênicas, morte extensiva de peixes e aumento do custo de tratamento de águas para abastecimento (AZEVEDO, 1998).

Entre os fatores que levam as cianobactérias a predominarem sobre os outros grupos fitoplanctônicos (microalgas), destacam-se as características fisiológicas pelas quais as cianobactérias assimilam os nutrientes $(\mathrm{N}$ e $\mathrm{P})$ do meio aquático. De maneira geral, as cianobactérias são menos eficientes na assimilação desses nutrientes do que as microalgas (algas verdes ou diatomáceas, por exemplo), que, em condições normais, crescem com maior facilidade e intensidade. No entanto, ao produzir uma descarga excessiva de nutrientes nos reservatórios, o homem propicia uma maior oferta desses nutrientes, facilitando assim, a assimilação dos mesmos com predominância das cianobactérias (FUNASA, 2003).

O tipo mais comum de intoxicação envolvendo cianobactérias está associado às hepatotoxinas, cujas espécies já identificadas como produtoras estão incluídas nos gêneros Microcystis, Anabaena, Nodularia, Planktothrix (Oscillatoria), Nostoc e Cylindrospermopsis (REBOUÇAS, BRAGA E TUNDISI, 2006).

Além de ocorrerem em lagos, rios e reservatórios de água doce e águas costeiras, as cianobactérias também podem estar presentes nas lagoas de estabilização para tratamento biológico dos esgotos provenientes de áreas urbanas e estabelecimentos comerciais e domésticos. Esta técnica de tratamento apresenta baixo custo, simplicidade operacional, boa eficiência para remoção de matéria orgânica e patógenos e é caracterizada pelo crescimento excessivo de organismos fitoplânctônicos cujo grupo 
comumente encontrado são as algas verdes (clorofíceas) e as cianobactérias (GODOY, 2007).

Os bioensaios foram introduzidos na Resolução №. 357/05 do Conselho Nacional do Meio Ambiente - CONAMA estabelecendo que o efluente não deverá causar ou possuir potencial para causar efeitos tóxicos aos organismos aquáticos no corpo receptor e que os critérios de toxicidade devem se basear em resultados de ensaios de ecotoxicidade padronizados utilizando organismos aquáticos.

Devido à complexidade do ambiente aquático e ao grande número de processos aos quais está sujeito um contaminante, é difícil extrapolar para escala ambiental as informações provenientes dos testes de toxicidade realizados em laboratório. Além disso, deve-se considerar que, à princípio, devido às diversas condições abióticas e bióticas presentes nos ecossistemas aquáticos, não há nenhum organismo modelo nem comunidade ecológica que possa ser usado para avaliar todos os efeitos possíveis sobre esses ecossistemas. Para que os efeitos em escala ambiental pudessem ser preditos a partir dos testes de toxicidade, as informações toxicológicas deveriam ser conectadas a modelos populacionais,pois envolve uma série de restrições, principalmente de custo e tempo e requer a atuação de equipe técnica multidiciplinar. Apesar disso, os testes de toxicidade realizados sob condições controladas e padronizadas vêm servindo como fonte de informações para avaliar os efeitos ecotoxicológicos de contaminantes (MAGALHÃES, FERRÃO FILHO, 2008).

\section{DESENVOLVIMENTO}

\subsection{Objetivos}

O objetivo geral desse trabalho foi avaliar a toxicidade de extratos de três cepas de cianobactérias Microcystis, uma não toxigênica $M$. sp. NPDC, e duas cepas comprovadamente toxigênicas, $M$ sp. TAC95 e $M$ sp. NPLJ4, com diferentes organismosteste. 


\subsection{Material e Métodos}

\subsubsection{Culturas e extratos de cepas de cianobactérias}

Nesse estudo foram utilizadas 2 cepas de Microcystis comprovadamente toxigênicas: TAC95 (predominantemente produtora de microcistinas - MCs em elevadas concentrações) e NPLJ4 (predominantemente produtora de [D-Leu ${ }^{1}$ ]MC-LR em elevadas concentrações) e NPDC (não produtora de MCs em concentrações significativas).

Os cultivos foram realizados em meio ASM-1 estéril em erlenmeyers com volume de $3 \mathrm{~L}$ mantidos em incubadora de BOD, sob aeração contínua e condições controladas de temperatura $25 \pm 1^{\circ} \mathrm{C}$ e iluminação da ordem de $35 \mu \mathrm{E} . \mathrm{m}^{-2} \mathrm{~s}^{-1}$ com fotoperíodo de 12 $h \mathrm{~d}^{-1}$.

Após 20 a 30 dias (final da fase de crescimento exponencial), as culturas foram concentradas por centrifugação a $1000 \mathrm{~g}$ por $10 \mathrm{~min}$ a $4^{\circ} \mathrm{C}$, e o pellet obtido, congelado a - $20^{\circ} \mathrm{C}$ e liofilizado. O material liofilizado foi submetido à extração pela repetição de 3 séries de congelamento / descongelamento, filtrado em membrana com porosidade média de $0,45 \mu \mathrm{m}$ e mantido a $-20^{\circ} \mathrm{C}$ até o uso.

A quantificação de MCs totais dos extratos foi realizada por imunoensaio ELISA (Enzyme-linked immunosorbent assay) / kits de placas (Beacon Analytical Systems Inc.). As amostras foram previamente filtradas em filtro tipo GF/C ou similar e em seguida, diluídas em água ultrapura de forma a possibilitar a quantificação pela curva de calibração com faixa entre 0 e $2,0 \mu \mathrm{g} \mathrm{L}^{-1}$ de MCs totais. O limite de detecção do método é de 0,16 $\mu \mathrm{g}$ $\mathrm{L}^{-1}$.

\subsubsection{Ensaios de ecotoxicidade em Artemia salina}

Devido à inexistência de um protocolo padronizado para ensaio de ecotoxicidade em Artemia salina, os testes foram baseados na norma da Petrobrás N-2588 (1996) com adaptações, após testes preliminares sobre o comportamento desse organismo em função da variação de alguns parâmetros e condições. De acordo com os resultados obtidos foi verificado que o teste deve ser realizado com o ajuste do $\mathrm{pH}$ das amostras para valores entre 8-9, além de manter condição mínima de 10\% de solução salina para 
que não haja comprometimento na interpretação dos resultados em relação à toxicidade da amostra testada.

Para a eclosão dos ovos de $A$. salina, estes foram incubados por 48 horas em solução salina artificial com pH entre 8 e 9 e à temperatura de $27^{\circ}$ a $30^{\circ} \mathrm{C}$ com iluminação constante de 60 - 100 W. Para isso, foi utilizada uma caixa plástica compartimentada por divisória contendo orifícios (da ordem de $2 \mathrm{~mm}$ ) uniformemente distribuídos, de forma a permitir a passagem de náuplios de $A$. salina, por fototropismo, após impedimento de passagem de luz em um dos compartimentos com papel alumínio.

Os ensaios foram realizados em tubos de ensaio de $10 \mathrm{~mL}$ em 4 réplicas para cada uma das concentrações de extrato de cianobactéria limitados a $90 \%$ com ajuste de $\mathrm{pH}$ para 8-9, controles negativo e positivo para um volume total de $5 \mathrm{~mL}$. Após a preparação de todos os tubos com as concentrações preestabelecidas, com o auxílio de uma pipeta Pasteur de diâmetro adequado e ponta arredondada, colocou-se 10 náuplios de $A$. salina por tubo, e estes foram mantidos sob iluminação à temperatura de $27^{\circ}$ a $30^{\circ}$ C por 24 h. O controle negativo (branco) foi realizado com a solução salina e o controle positivo, com solução de dicromato de potássio em meio salino com concentração de 0,2 $\mathrm{g} \mathrm{L}^{-1}$. Após a exposição de $24 \mathrm{~h}$, o número de organismos vivos e mortos em cada tubo era quantificado para posteriormente, determinar a concentração da amostra que causou mortalidade de $50 \%$ dos organismos após exposição de $24 \mathrm{~h}$ - $\mathrm{CL}_{50} \mathrm{H}_{24 \mathrm{~h}}$ nas condições do teste. A CL50 $24 \mathrm{~h}$ foi obtida por cálculo estatístico usando o programa Trimmed SpearmanKarber (Hamilton et al., 1977) com intervalo de confiança de 95\%.

\subsubsection{Manutenção e cultivo de Ceriodaphnia dubia e Daphnia magna}

As cepas de Ceriodaphnia dubia e Daphnia magna foram mantidas à temperatura controlada de 25ㅇ $\mathrm{C}$ e iluminação de $35 \mu \mathrm{E} \cdot \mathrm{m}^{-2} \mathrm{~s}^{-1}$ com fotoperíodo de $12 \mathrm{~h} \mathrm{~d}^{-1}$ em incubadora BOD. Os cultivos foram realizados seguindo normas padronizadas da ABNT, 2005 - NBR 13373 para C. dubia e da ABNT, 2004- NBR 12713 para D. magna em meios específicos (água reconstituída e M4, respectivamente) previamente aerados por um período mínimo de $12 \mathrm{~h}$ antes da sua utilização. A renovação da água de cultivo das culturas estoque e a alimentação foi realizada 3 vezes por semana. 
Os organismos foram alimentados com uma suspensão algácea de Pseudokirchneriella subcapitata concentrados na fase exponencial de crescimento, para uma concentração de $1 \times 10^{5}$ cél $\mathrm{mL}^{-1} \mathrm{org}^{-1}$ e alimento composto constituído de levedura (fermento biológico seco dissolvido em água deionizada) e ração de peixe Tetramim fermentada (na proporção de 1:1) para uma concentração de $1 \mathrm{~mL} \mathrm{~L}^{-1}$.

\subsubsection{Ensaios de ecotoxicidade em Ceriodaphnia dubia e Daphnia magna}

Os ensaios de ecotoxicidade utilizando C. dubia e D. magna consistiram na exposição, em 3 réplicas, de 5 neonatas com idade entre 6 e $24 \mathrm{~h}$ para diferentes diluições das amostras de extratos de cepas de cianobactérias com o meio específico para volume total de $10 \mathrm{~mL}$ em placas de cultivo celular em polipropileno (TPP). Os experimentos foram mantidos a temperatura controlada de $25^{\circ} \mathrm{C}$, sem iluminação e alimentação.

Os ensaios foram validados pelos controles negativo (água recontituída) e positivo (dicromato de potássio $0,2 \mathrm{~g} \mathrm{~L}^{-1}$ ) e atendimento aos valores preestabelecidos dos parâmetros: pH entre 5 e 9, condutividade, dureza e oxigênio dissolvido (OD) superior a 1 e $3 \mathrm{mg} \mathrm{L}^{-1}$ para $C$. dubia e $D$. magna, respectivamente.

Após o período de exposição (24 e 48 horas) foi realizada a contagem dos organismos imóveis ou mortos em esteroscópio e seus resultados foram expressos como concentração efetiva mediana da amostra que causa efeito a $50 \%$ da população exposta após $24 \mathrm{~h}$ - $\mathrm{CE} 50_{24 \mathrm{~h}}$ e $48 \mathrm{~h}$ - CE50 $48 \mathrm{~h}$ obtidas por cálculo estatístico usando o programa Trimmed Spearman-Karber com intervalo de confiança de 95\% (Hamilton et al. 1977). Finalmente, os resultados dos ensaios foram validados se a porcentagem de organismos imóveis ou mortos no controle negativo resultasse inferior a 10\% (ABNT, 2004).

\subsubsection{Manutenção e cultivo de Pseudokirchneriella subcapitata}

A cepa de $P$. subcapitata foi mantida por inoculações quinzenais sob o bico de Bunsen em meio ASM-1 estéril, autoclavado a $121^{\circ} \mathrm{C}$ durante 20 minutos. A cultura foi mantida em triplicata em tubos de ensaio de $22 \mathrm{~mL}$ contendo $10 \mathrm{~mL}$ de meio e em erlenmeyers de $250 \mathrm{~mL}$ com $100 \mathrm{~mL}$ de meio à temperatura controlada de $25^{\circ} \mathrm{C}$ e 
iluminação de $35 \mu \mathrm{E} \mathrm{m} \mathrm{m}^{-2} \mathrm{~s}^{-1}$ com fotoperíodo de $12 \mathrm{~h} \mathrm{~d}^{-1} \mathrm{em}$ incubadora BOD e agitação diária ou aeração contínua.

\subsubsection{Ensaio de ecotoxicidade em Pseudokirchneriella subcapitata}

O protocolo utilizado para a realização dos testes em $P$. subcapitata foram baseados na metodologia de Blaise et al., 2000. A validade dos testes para este ensaio de ecotoxicidade foi condicionada as seguintes premissas: o coeficiente de variação de cinco amostras controle, com tempo de exposição igual a 72 horas, não pode exceder a $40 \%$; e a densidade celular nos frascos de controle deve aumentar por um fator de no

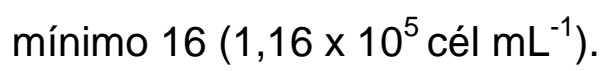

Para o ensaio, as diferentes concentrações das amostras de extratos de cepas de cianobactérias diluídas com solução tampão de bicarbonato de sódio, foram preparadas em vials de $5 \mathrm{~mL}$ contendo $2,5 \mathrm{~mL}$ de volume total, onde populações estimadas de $P$. subcapitata da ordem de $1,04 \times 10^{4}$ cél $\mathrm{mL}^{-1}$ foram expostas. Estes frascos permaneceram vedados com filme plástico transparente e incubados sob luz contínua por $72 \mathrm{~h}$ e a uma temperatura de $25^{\circ} \mathrm{C}$ sob mesa agitadora.

Após este período, foi avaliada a toxicidade por meio da \% de inibição realizandose a contagem das células com auxílio de microscópio óptico, em câmara de Neubauer e os resultados foram tratados no programa estatístico Trimmed Spearman-Karber (HAMILTON et al., 1977) com intervalo de confiança de $95 \%$ e expressos em CE50 ${ }_{72 h}$ concentração efetiva média que causa um efeito crônico a $50 \%$ dos organismos após $72 \mathrm{~h}$ de exposição.

\subsection{Resultados e Discussão}

Nos ensaios de ecotoxicidade crônica em Pseudokirchneriella subcapitata foi avaliado o efeito de inibição após $72 \mathrm{~h}$ de exposição. Já nos ensaios de ecotoxicidade aguda em Ceriodaphnia dubia, Daphnia magna e Artemia salina foram avaliados os efeitos de imobilidade e ou letalidade após 24 e $48 \mathrm{~h}$ de exposição para $C$. dubia e $D$. magna e de letalidade após $24 \mathrm{~h}$ de exposição para $A$. salina. 
Nos Gráficos 1 a 3 são apresentados os resultados obtidos para os ensaios de ecotoxicidade em A. salina, D. magna, $C$. dubia e P.subcapitata para os extratos de cepas de cianobactérias Microcystis: $M$. sp. NPDC, M. sp. NPLJ4 e M. sp. TAC95, respectivamente.

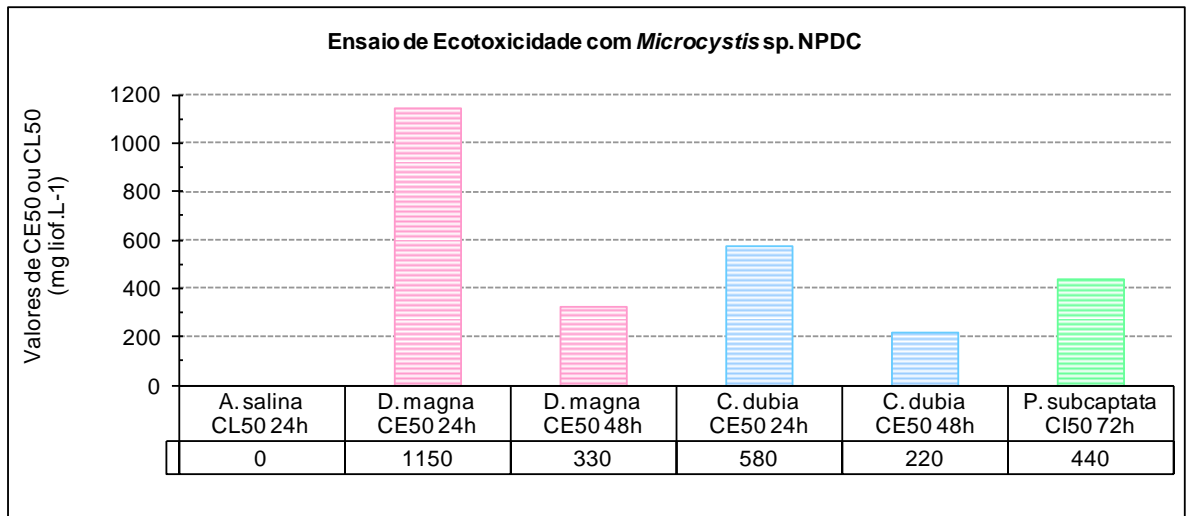

Gráfico 1 - Ensaio de Ecotoxicidade em A. salina, D. magna, C. dubia e P.subcapitata para extrato de M. sp. NPDC

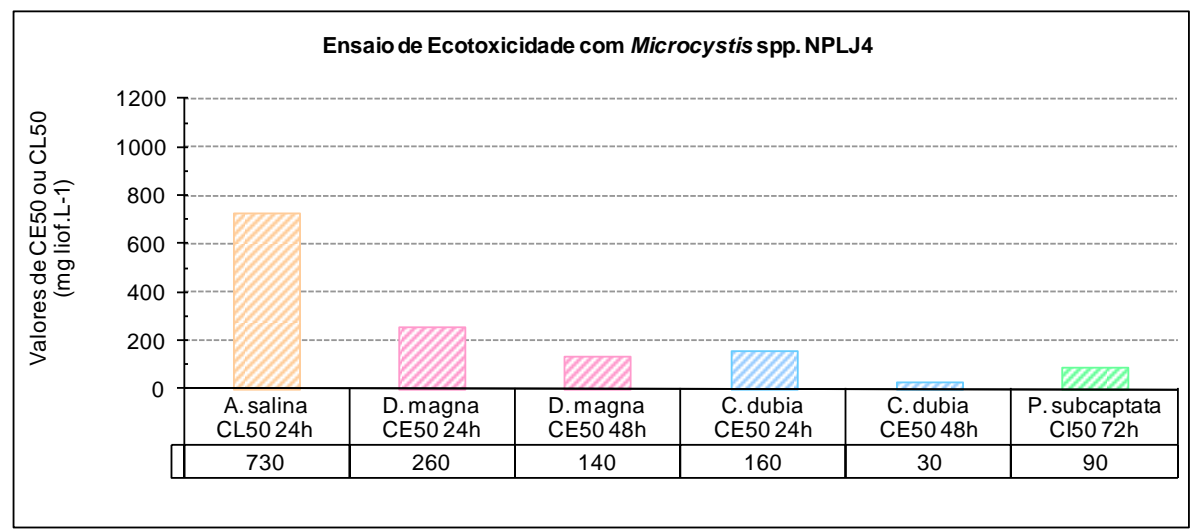

Gráfico 2- Ensaio de Ecotoxicidade em A. salina, D. magna, C. dubia e P.subcapitata para extrato de M. spp. NPLJ4 


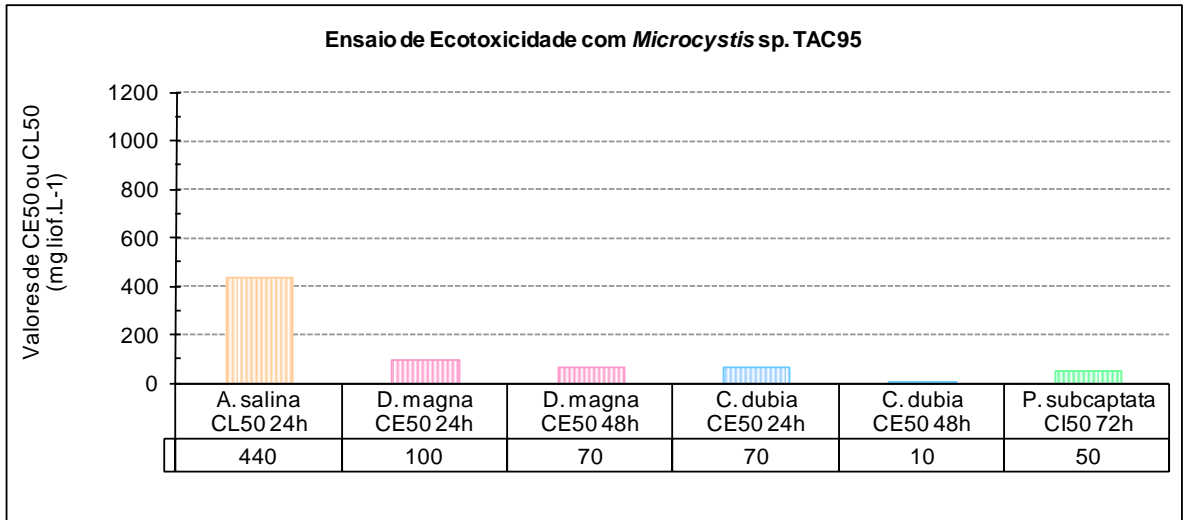

Gráfico 3- Ensaio de Ecotoxicidade em A. salina, D. magna, C. dubia e P.subcapitata para extrato de M. $s p$. TAC95

Na Tabela 1 são apresentados os valores de CE50,CL50 e Cl50 em concentração de liofilizado (mg liof $\mathrm{L}^{-1}$ ) e em concentração de microcistinas - MCs ( $\mu \mathrm{g} \mathrm{MCs} \mathrm{L}^{-1}$ ) obtidos nos ensaios de ecotoxicidade em $A$. salina, $D$. magna, $C$. dubia e $P$.subcapitata para os extratos de cepas de cianobactérias Microcystis: $M$. sp. NPDC, M. sp. NPLJ4 e M. sp. TAC95.

Tabela 1 - Valores de CE50 e CL50 em concentração de liofilizado (mg liof $\left.\mathrm{L}^{-1}\right)$ e em concentração de MCs ( $\mu \mathrm{g} \mathrm{MC} \mathrm{L}^{-1}$ ) obtidos nos ensaios de ecotoxicidade em A. salina, D. magna, $C$. dubia e P.subcapitata para os extratos das cepas de cianobactérias / Microcystis: M. sp. NPDC, M. sp.

TAC95 e M. sp. NPLJ4

\begin{tabular}{|c|c|c|c|c|c|c|c|}
\hline & \multicolumn{2}{|c|}{ Microcystis sp. NPDC } & \multicolumn{2}{|c|}{ Microcystis sp. NPLJ4 } & \multicolumn{2}{|c|}{ Microcystis sp. TAC95 } & \multirow{2}{*}{$\begin{array}{c}\text { Referência } \\
{\left[\mu \mathrm{g} M C s . L^{-1}\right]}\end{array}$} \\
\hline Organismos-teste & {$\left[\mathrm{mg}\right.$ liof. $\left.\mathrm{L}^{-1}\right]$} & {$\left[\mu \mathrm{g} M C s . L^{-1}\right]$} & [mg liof. $\left.\mathrm{L}^{-1}\right]$ & {$\left[\mu \mathrm{g} \mathrm{MCs} . \mathrm{L}^{-1}\right]$} & [mg liof. $\left.L^{-1}\right]$ & {$\left[\mu \mathrm{g} \mathrm{MCs} . \mathrm{L}^{-1}\right]$} & \\
\hline A. salina $C L 50_{24 h}$ & $>1200$ & n.d. & 730,0 & 5717,1 & 440,0 & 3675,1 & $\begin{array}{l}8000 \text { e } 2000^{(a)} \\
\text { (Lindsay, 2006) }\end{array}$ \\
\hline D. magna CE50 $24 \mathrm{~h}$ & 1150 & 1,9 & 260,0 & 2036,2 & 100,0 & 835,2 & \multirow{2}{*}{$\begin{array}{c}3750 \text { e } 770^{(b)} \\
\text { (Ferrão Filho, } \\
2009)\end{array}$} \\
\hline D. magna $\mathrm{CE} 5 \mathrm{O}_{48 \mathrm{~h}}$ & 330 & 0,5 & 140,0 & 1096,4 & 70,0 & 584,7 & \\
\hline C. dubia $C E 50_{24 h}$ & 580 & 0,9 & 160,0 & 1253,1 & 70,0 & 584,7 & \multirow{2}{*}{$\begin{array}{l}1210 \text { e } 220^{(\mathrm{c})} \\
\text { (Ferrão Filho, } \\
2009)\end{array}$} \\
\hline C. dubia $C E 50_{48 h}$ & 220 & 0,4 & 30,0 & 234,9 & 10,0 & 83,5 & \\
\hline P. subcapitata $\mathrm{Cl} 5 \mathrm{O}_{72 \mathrm{~h}}$ & 440 & 0,7 & 90,0 & 704,8 & 50,0 & 417,6 & - \\
\hline
\end{tabular}

n.d.: toxicidade $C \mathrm{LSO}_{24 \mathrm{~h}}$ não detectada;

(a): Faixa de valores de $\mathrm{CL5O}_{24 h}$ obtida por Lindsay (2006) com A. salina para cepa tóxica de M. aeruginosa PCC7813;

(b): Faixa de valores de $C E 50_{24 h}$ obtida por Ferrão Filho (2009) com Daphnia pulicaria para cepa tóxica de M. aeruginosa NPLJ3;

(c): Faixa de valores de $\mathrm{CE} 5 \mathrm{O}_{24 h}$ obtida por Ferrão Filho (2009) com Daphnia pulex para cepa tóxica de M. aeruginosa NPLJ3; 
Não foi possível determinar a $\mathrm{CL}_{24} \mathrm{2}_{2 \mathrm{~h}}$ com Artemia salina para o extrato da cepa

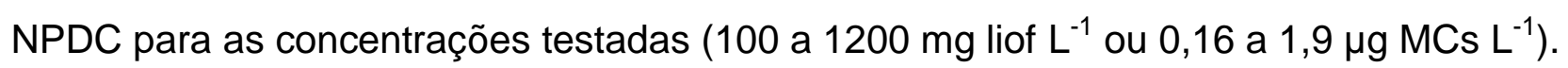

Os valores obtidos de $\mathrm{CL}_{24}$ com $A$. salina para o extrato da cepa NPLJ4, produtora de [D-Leu ${ }^{1}$ ] MC-LR em elevadas concentrações, foi de $730 \mathrm{mg}^{\text {liof.L }}{ }^{-1}$ (5717,1 $\mu \mathrm{g} M \mathrm{MS}^{-1}{ }^{-1}$ ). Para o extrato da cepa toxigênica TAC95, produtora de MC-LR em elevadas concentrações, o valor de $\mathrm{CL}_{24}{ }_{24 \mathrm{~h}}$ com $A$. salina foi de $440 \mathrm{mg}$ liof. $\mathrm{L}^{-1}$ (3675,1 $\mu \mathrm{g}$ MCs L $\mathrm{L}^{-}$ $\left.{ }^{1}\right)$. Estes resultados indicam que para Artemia salina, a toxicidade do extrato da cepa TAC95 é maior do que a da NPLJ4. Resultados similares foram encontrados por Lindsay et al. (2006) para a cepa tóxica de Microcystis aeruginosa PCC7813, que produz predominantemente a MC-LR, tendo obtido para Artemia salina valores de $\mathrm{CL}_{24} \mathrm{H}_{24}$ compreendidos na faixa entre 2000 e $8000 \mathrm{mg} \mathrm{MCs} \mathrm{L}^{-1}$.

Os valores obtidos de CE50 com Daphnia magna para o extrato da cepa NPDC

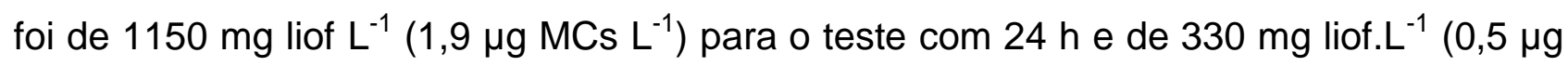
$\left.M C s L^{-1}\right)$ para o teste com $48 \mathrm{~h}$. Para o extrato da cepa NPLJ4, a CE50 com D. magna calculada foi de $260 \mathrm{mg}$ liof $\mathrm{L}^{-1}\left(2036,2 \mu \mathrm{g} \mathrm{MCs} \mathrm{L}^{-1}\right)$ para o teste com $24 \mathrm{~h}$ e de $140 \mathrm{mg}$ liof $\mathrm{L}^{-1}\left(1096,4 \mu \mathrm{g} \mathrm{MCs} \mathrm{L}^{-1}\right)$ para o teste com $48 \mathrm{~h}$. Para o extrato da cepa TAC95, o valor de

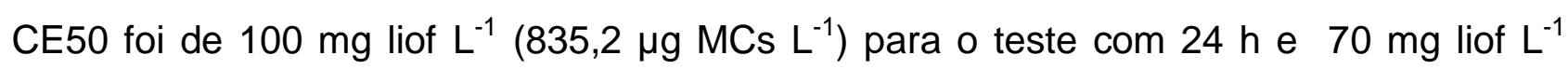

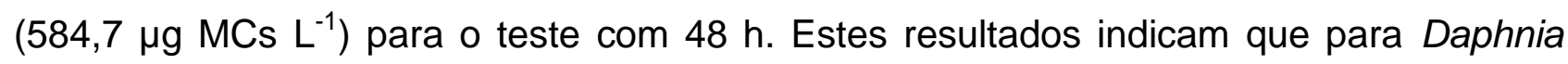
magna, a toxicidade do extrato da cepa TAC95 foi maior do que a do extrato de NPLJ4, sendo este, maior do que a do extrato de NPDC.

- Comparando-se os valores de $\mathrm{CE} 50_{24 \mathrm{~h}}$ em concentração de liofilizado com D. magna para o extratos das cepas NPLJ4, TAC95 e NPDC, pode-se observar que, de forma geral:a toxicidade do extrato da cepa TAC95 resultou cerca de 2,2 vezes maior do que a do extrato de NPLJ4;

- a toxicidade do extrato da cepa NPLJ4 resultou cerca de 4,3 vezes maior do que a do extrato de NPDC.

Ferrão Filho (2009) usando como organismo-teste a Daphnia pulicaria para a cepa tóxica de Microcystis aeruginosa NPLJ3, isolada do mesmo local da cepa NPLJ4, obteve valores de CE50 em concentração de MCs compreendidos na faixa entre 3750 e $770 \mu \mathrm{g} \mathrm{MCs} \mathrm{L^{-1 }}$, o que condiz com os resultados obtidos de CE50 para Daphnia magna de

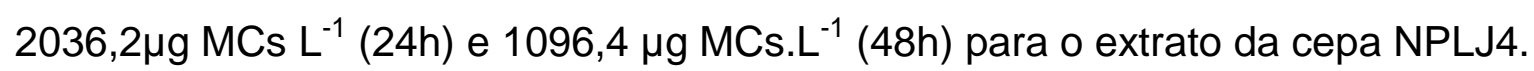


Os valores obtidos de CE50 com Ceriodaphnia dubia para o extrato da cepa NPDC foi de $580 \mathrm{mg}$ liof $L^{-1}\left(0,9 \mu \mathrm{MCs} \mathrm{L}^{-1}\right)$ para o teste com $24 \mathrm{~h}$ e $220 \mathrm{mg}$ liof L $\mathrm{L}^{-1}(0,4$ $\mu \mathrm{g}$ MCs $\mathrm{L}^{-1}$ ) para o teste com $48 \mathrm{~h}$. Para o extrato da cepa NPLJ4 a CE50 foi de $160 \mathrm{mg}$

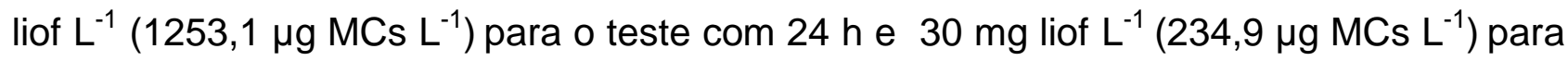
o teste com $48 \mathrm{~h}$. Para o extrato da cepa TAC95, o valor de CE50 foi de $70 \mathrm{mg}$ liof L $\mathrm{L}^{-1}$

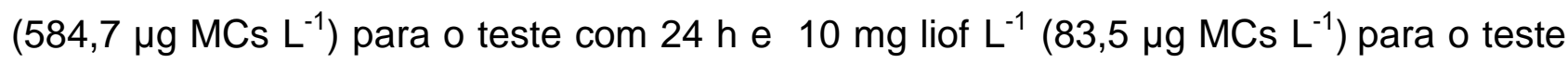
com 48 h. Estes valores indicam que para Ceriodaphnia dubia, a ordem crescente de toxicidade correspondente aos extratos das cepas foi NPDC, NPLJ4 e TAC95.

Segundo Ferrão Filho (2009) para a cepa Microcystis aeruginosa NPLJ3 e com o organismo-teste Daphnia pulex, de sensibilidade comparável à da Ceriodaphnia dubia, a

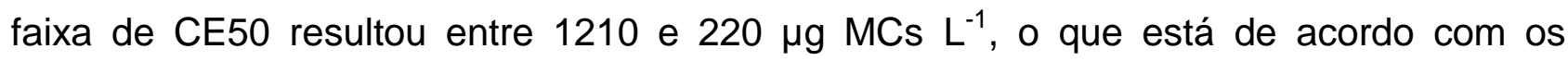
resultados obtidos de CE50 para Ceriodaphnia dubia, para o extrato da cepa NPLJ4 com valores de CE50 234,9 a 1253,1 $\mu \mathrm{gCs} \mathrm{L}^{-1}$.

Os valores obtidos de CE50 $72 \mathrm{~h}$ para o teste crônico com Pseudokirchneriella

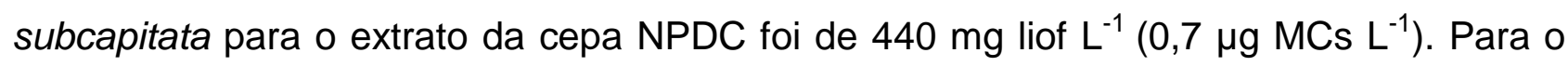

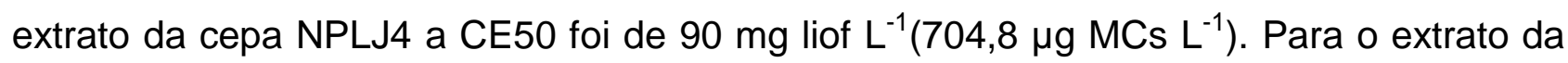

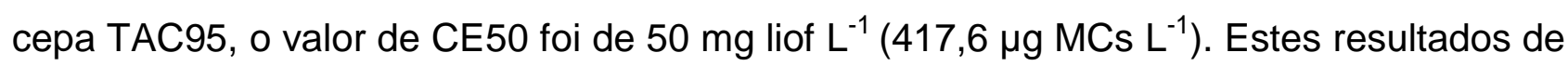
CI50 para Pseudokirchneriella subcapitata, apontam a ordem de toxicidade crescente correspondente aos extratos das cepas foi NPDC, NPLJ4 e TAC95.

Segundo Ferrão Filho (2009), dentre as cianotoxinas, as MCs foram as mais estudadas quanto ao seu efeito sobre o zooplâncton (DEMOTT et al. 1991, JUNGMANN \& BENNDORF 1994). Apesar das evidências de que as MCs causam efeitos adversos em diversas espécies de zooplâncton, outros compostos produzidos pelas cianobactérias podem estar relacionados com a toxicidade para o zooplâncton. Os valores de CE50 obtidos neste trabalho com Daphnia magna e Ceriodaphnia dubia, e de Cl50 com Pseudokirchneriella subcapitata para o extrato da cepa NPDC, com baixas concentrações de MCs (entre 0,4 e 1,9 $\mu \mathrm{g}$ MCs $\mathrm{L}^{-1}$ ) confirmam esta constatação, uma vez que foi constatada toxicidade, mesmo para o extrato da cepa NPDC, produtora de MCs em baixas concentrações.

Em relação as concentrações de MCs presentes nos extratos das cepas de cianobactérias / Microcystis, a resposta de toxicidade obtida para $A$. salina foi a mais coerente dentre os organismos-teste utilizados, uma vez que não foi possível determinar o 
valor de $\mathrm{CL}_{50} 0_{24 \mathrm{~h}}$ para a cepa NPDC e os valores de $\mathrm{CL} 50_{24 \mathrm{~h}}$ para as cepas NPLJ4 e TAC95 foram condizentes com as respostas obtidas para os demais organismos-teste.

A Tabela 2 e o Gráfico 4 mostram os valores obtidos de Fator de Toxicidade FT, ou seja, a menor concentração da amostra, em \% (massa:massa) na qual não se observou o efeito deletério sobre os organismos-teste: A. salina, D. magna, C. dubia e P.subcapitata. O anexo 7 da RESOLUÇÃO №. 0070/2009 - CEMA estabelece condições e padrões de lançamento de efluentes líquidos industriais e limita o valor de FT de 8 (12,5\%) em Daphnia magna e Vibrio fischeri para efluentes provenientes de outras atividades, quando não enquadradas às especificadas na referida resolução.

Tabela 2- Fator de Toxicidade - FT dos extratos das cepas de cianobactérias/

Microcystis em relação aos organismos testados

\begin{tabular}{c|c|c|c}
\hline Organismo-teste & $\begin{array}{l}\text { Microcystis sp. } \\
\text { NPDC }\end{array}$ & $\begin{array}{l}\text { Microcystis spp. } \\
\text { NPLJ4 }\end{array}$ & $\begin{array}{l}\text { Microcystis sp. } \\
\text { TAC95 }\end{array}$ \\
\hline A. salina CL5024h & $<833$ & 10000 & 20000 \\
\hline D. magna CE5024h & 10000 & 20000 & 1000000 \\
\hline D. magna CE5048h & 20000 & 20000 & 1000000 \\
\hline C. dubia CE5024h & 10000 & 20000 & 1000000 \\
\hline C. dubia CE5048h & 20000 & 20000 & $>00000$ \\
\hline P. subcapitata CI5072h & 20000 & 40000 & $>40000$ \\
\hline
\end{tabular}

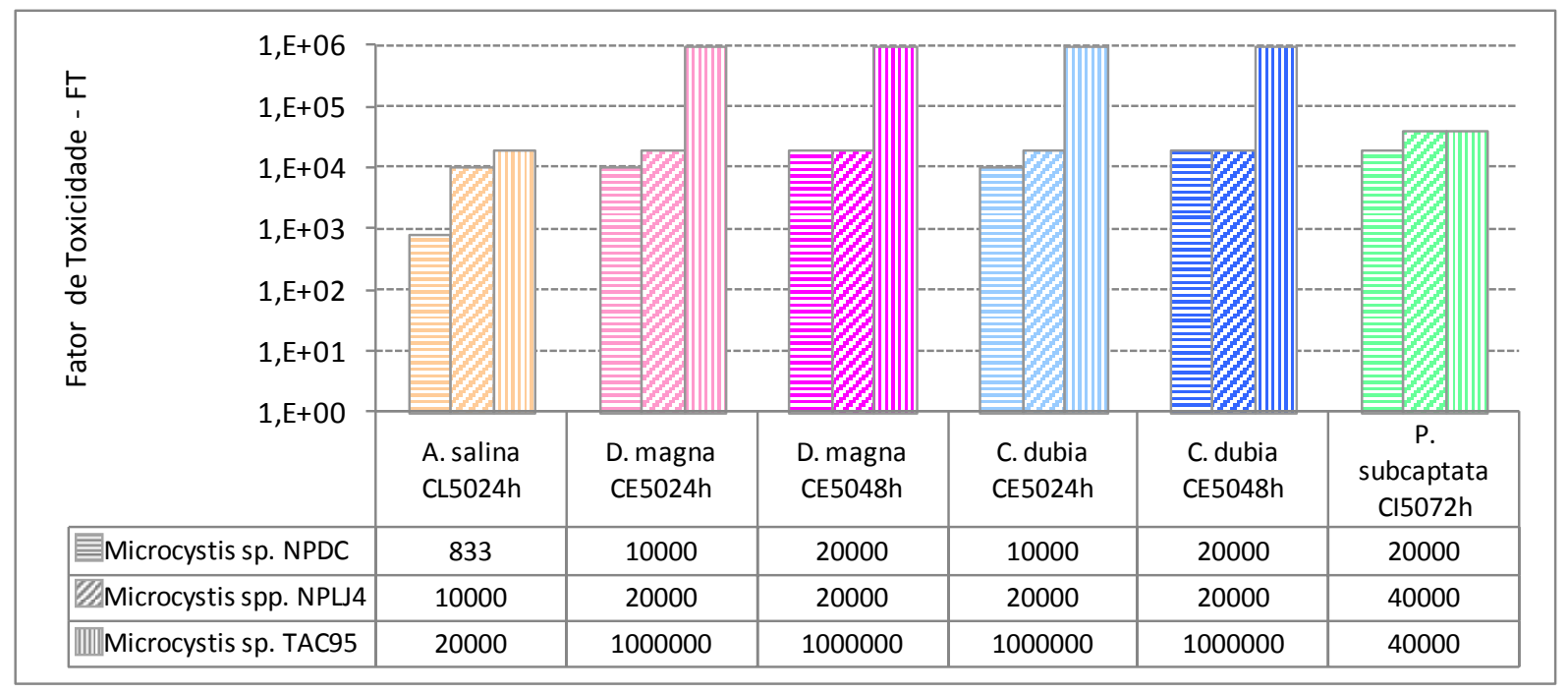

Gráfico 4- Fator de Toxicidade - FT dos extratos das cepas de cianobactérias/ Microcystis em relação aos organismos testados 
Os valores de FT obtidos mostraram que todos os extratos das cepas de cianobactérias / Microcystis apresentaram elevada toxicidade. Pelos valores apresentados, pode-se observar para todos os organismos-teste os extratos das cepas apresentaram valores de FT bem superiores ao limite estabelecido (FT:8), mesmo para o extrato da cepa NPDC, com concentrações reduzidas de MCs $\left(0,4\right.$ a $\left.1,9 \mu \mathrm{gCs} \mathrm{L}^{-1}\right)$. No entanto, os resultados foram coerentes para os organismos testados $A$. salina, $D$. magna, C. dubia e P.subcapitata, confirmando assim, a ordem crescente de toxicidade correspondente aos extratos das cepas NPDC, NPLJ4 e TAC95.

O § 3 do Artigo 18 da Resolução no 430/2011 do Conselho Nacional do Meio Ambiente - CONAMA estabelece as diretrizes a serem seguidas na ausência de critérios de ecotoxicidade, estabelecidos pelo órgão ambiental para avaliar o efeito tóxico do efluente no corpo receptor. Para efluentes lançados em corpos receptores de águas doces Classes 1 e 2, e águas salinas e salobras Classe 1, a Concentração do Efluente no Corpo Receptor - CECR deve ser menor ou igual à Concentração de Efeito Não Observado - CENO de pelo menos dois níveis tróficos, ou seja CECR deve ser menor ou igual ao valor da Concentração Letal Mediana - CL50 dividida por 10; ou menor ou igual a 30 dividido pelo FT quando for realizado teste de ecotoxicidade para medir o efeito tóxico agudo. Para efluentes lançados em corpos receptores de água doce Classe 3 , e águas salinas e salobras Classe 2, a Concentração do Efluente no Corpo Receptor-CECR deve ser menor ou igual ao valor da CL50 dividida por 3 ou menor ou igual a 100 dividido pelo FT, quando for realizado teste de ecotoxicidade aguda.

Vale ressaltar que de forma similar ao estabelecido $\S 3$ do Artigo 18 da Resolução no 430/2011 do CONAMA, os Artigos 10 e 11 da Resolução 081/2010 do Conselho Estadual do Meio Ambiente - CEMA, referentes ao lançamento de efluentes em corpos receptores de água, estabelece que a CECR deve ser menor ou igual à concentração que não cause efeito crônico aos organismos aquáticos de pelo menos dois níveis tróficos. Para os efluentes lançados em corpos receptores de águas doces enquadrados nas Classes 1 ou 2 e nas águas salinas ou salobras Classe 1, a CECR deve ser menor ou igual a 30 divididos pelo FT do efluente, quando for realizado ensaio de ecotoxicidade para medir efeito tóxico agudo. Para os efluentes lançados em corpos receptores de águas doces enquadrados nas Classe 3 ou 4 e salinas ou salobras Classe 2 e 3 , a CECR deve ser menor ou igual a 100 dividido pelo FT. 
Para os resultados obtidos neste trabalho, os valores calculados de CECR, considerando os valores de FT, em atendimento à Resolução 081/2010 do CEMA foram mais restritivos em relação aos calculados considerando os valores de CL50, CE50 e Cl50, de acordo com a Resolução $n^{\circ} 430 / 2011$ do CONAMA. Mesmo assim, vale ressaltar que, para ambas condições de cálculo e extratos utilizados, muito dificilmente estes poderiam ser lançados em corpos receptores, sem transgredir as legislações vigentes.

\section{CONCLUSÃO}

Em relação aos ensaios de ecotoxicidade em Artemia salina, Daphnia magna, Ceriodaphnia dubia e Pseudokirchneriella subcapitata para os extratos de cepas de cianobactérias Microcystis: M. sp. NPDC, M. sp. NPLJ4 e M. sp. TAC95, pode-se concluir que:

- Os valores obtidos de CL50, CE50 e Cl50 indicaram que para os organismos utilizados $A$. salina, D. magna, $C$. dubia e $P$. subcapitata a ordem crescente de toxicidade correspondente aos extratos das cepas foi NPDC, NPLJ4 e TAC95;

- Os valores de Fator de Toxicidade - FT obtidos mostraram que todos os extratos das cepas de cianobactérias / Microcystis apresentaram elevada toxicidade, tendo apresentado valores de FT bem superiores ao limite estabelecido (FT:8).

- O extrato da cepa M. sp. NPDC, com concentrações de liofilizado entre 220 e $1150 \mathrm{mg}$ liof. $\mathrm{L}^{-1}$ foi tóxico para os organismos-teste Daphnia magna, Ceriodaphnia dubia e Pseudokirchneriella subcapitata, provavelmente devido a outros compostos presentes no extrato, uma vez que as concentrações de MCs resultaram reduzidas $\left(0,4\right.$ a $\left.1,9 \mu \mathrm{g} \mathrm{MCs} \mathrm{L}^{-1}\right)$;

- Em relação as concentrações de MCs presentes nos extratos das cepas de cianobactérias / Microcystis, a resposta de toxicidade obtida para A. salina foi a mais coerente dentre os organismos-teste utilizados.

\section{REFERÊNCIAS}


AZEVEDO, S.M.F.O 1998. Toxinas de Cianobactérias: Causas e Consequências para a saúde pública. Medicina on line, 3(1):1-19.

ABNT. NBR 13373: Ecotoxicologia aquática - Toxicidade crônica - Método de ensaio com Ceriodaphnia spp (Crustacea, Cladocera). São Paulo, 2005, 15p.

ABNT. NBR 12713: Ecotoxicidade aguda - Método de ensaio com Dapnhia spp (Cladocera, Crustacea). São Paulo, 2004,21p.

BLAISE, C.; FORGET, G.; TROTTIER, S. Toxicity screening of aqueous samples using a cost-effective 72-h exposure Selenastrum capricornutum assay. Journal of Environmental Toxicology. New York, v. 15, p. 352-359, 2000. Special Issue:Watertox Bioassays.

BRASIL, Ministério do Meio Ambiente. Conselho Nacional de Meio Ambiente. Resolução $n^{\circ}$ 357, 17 de março de 2005. Dispõe sobre a classificação dos corpos de água e diretrizes ambientais para o seu enquadramento, bem como estabelece as condições e padrões de lançamento de efluentes, e dá outras providências. Brasília, 2005.

BRASIL, Ministério do Meio Ambiente. Conselho Nacional do Meio Ambiente. Resolução $n^{\circ} 430$ de 13 de maio de 2011. Complementa e altera a Resolução no 357 de 2005, Brasília, 2011.

FERRÃO FILHO, A.S. Bioacumulação de cianotoxinas e seus efeitos em organismos aquáticos. Oecol. Bras., 13(2): 272-312, 2009.

FUNASA- Fundação Nacional de Saúde, 2003. Cianobactérias Tóxicas na Água para Consumo Humano na Saúde Pública e Processos de Remoção em Água para Consumo Humano. Disponível em http://www.bvsms.saude.gov.br/bvs/publicacoes. Acessado em julho 2012.

GODOY, O. A. Avaliação da Presença de Cianobactérias em Efluentes de Sistema de Tratamento de Esgotos Sanitários por Lagoas de Estabilização Associadas a 
Tratamento Físico-Químico. Dissertação apresentada ao Programa de Pós-Graduação em Engenharia de Hidráulica e Sanitária. Universidade de São Paulo. São Paulo, 2007.

LINDSAY, J.; METCALF, J.S. \& CODD, G.A. 2006. Protection against the toxicity of microcystin-LR and cylindrospermopsin in Artemia salina and Daphnia spp. by pretreatment with cyanobacterial lipopolysaccharide (LPS). Toxicon, 48: 995-1001.

MAGALHÃES, D.P.; FERRÃO FILHO, A.S. A ecotoxicologia como ferramenta no biomonitoramento de ecossistemas aquáticos. Oecol. Bras. 12(3), p. 355-381, 2008.

PARANÁ, Conselho Nacional do Meio Ambiente. Resolução 0070/2009 - CEMA. Dispõe sobre o licenciamento ambiental, estabelece condições e critérios e dá outras providências, para Empreendimentos Industriais. Curitiba, 2009.

PARANÁ, Conselho Nacional do Meio Ambiente. Resolução 081/2010 - CEMA. Dispõe sobre Critérios e Padrões de ecotoxicidade para o Controle de Efluentes Líquidos lançados em águas superficiais no Estado do Paraná. Curitiba, 2010.

Petrobrás N-2588: Determinação da toxicidade aguda de agentes tóxicos em relação à Artemia sp. CONTEC - Comissão de normas técnicas, 1996.

REBOUÇAS, A. C. BRAGA, B. TUNDISI, J. G. Águas Doces no Brasil Capital Ecológico, Uso e Conservação, 3ª Edição, São Paulo: Editora Escrituras, 2006. 